\title{
Podiatrist care and outcomes for patients with diabetes and foot ulcer ${ }^{\dagger}$
}

\author{
Teresa B Gibson ${ }^{1}$, Vickie R Driver ${ }^{2}$, James S Wrobel ${ }^{3}$, James R Christina ${ }^{4}$, Erin Bagalman, \\ Roy DeFrancis ${ }^{5}$, Matthew G Garoufalis ${ }^{6}$, Ginger S Carls ${ }^{1}$ \& Justin Gatwood ${ }^{1}$ \\ 1 Truven Health Analytics, Ann Arbor, MI, USA \\ 2 VA New England Health Care Division, Department of Surgery, Providence, RI, USA \\ 3 Department of Internal Medicine, University of Michigan Medical School, Ann Arbor, MI, USA \\ 4 American Podiatric Medical Association, Bethesda, MD, USA \\ 5 Consultant, Buffalo, NY, USA \\ 6 American Podiatric Medical Association, Chicago, IL, USA \\ 7 Health Outcomes, Truven Health Analytics, DC, USA
}

\section{Key words}

Amputation; Diabetes; Foot ulcer; Podiatrist

\section{Correspondence to}

TB Gibson, Truven Health Analytics, 777 E. Eisenhower Parkway, Ann Arbor, MI 48108, USA

E-mail: teresa.gibson@truvenhealth.com

doi: 10.1111/iwj.12021
Gibson TB, Driver VR, Wrobel JS, Christina JR, Bagalman E, DeFrancis R, Garoufalis MG, Carls GS, Gatwood J. Podiatrist care and outcomes for patients with diabetes and foot ulcer. Int Wound J 2014; 11:641-648

\section{Abstract}

We examined whether outcomes of care (amputation and hospitalisation) among patients with diabetes and foot ulcer differ between those who received pre-ulcer care from podiatrists and those who did not. Adult patients with diabetes and a diagnosis of a diabetic foot ulcer were found in the MarketScan Databases, 2005-2008. Multivariate Cox proportional hazard models estimated the hazard of amputation and hospitalisation. Logistic regression estimated the likelihood of these events. Propensity score weighting and regression adjustment were used to adjust for potentially different characteristics of patients who did and did not receive podiatric care. The sample included 27545 patients aged greater than 65+ years (Medicare-eligible patients with employer-sponsored supplemental insurance) and 20208 patients aged lesser than 65 years (non-Medicare-eligible commercially insured patients). Care by podiatrists in the year prior to a diabetic foot ulcer was associated with a lower hazard of lower extremity amputation, major amputation and hospitalisations in both non-Medicareeligible commercially insured and Medicare-eligible patient populations. Systematic differences between patients with diabetes and foot ulcer, receiving and not receiving care from podiatrists were also observed; specifically, patients with diabetes receiving care from podiatrists tend to be older and sicker.

\section{Introduction}

Foot ulcers are a serious complication in patients with diabetes, with up to a $25 \%$ lifetime risk of foot ulceration in patients with diabetes (1). Foot ulcers result from degradation in the integumentary, vascular and nervous systems that typically occur in patients with long-standing diabetes mellitus. This environment permits acute or chronic repetitive trauma to frequently go unrecognised by the patient. If ulcers fail to heal and progress into deep infection or gangrene, amputation of the lower extremity may ensue, resulting in a $6-22 \%$ cumulative amputation rate for patients with ulcers (2). Most foot

\footnotetext{
${ }^{\dagger}$ An earlier version of this manuscript was presented as a Late-Breaking Abstract at the American Diabetes Association 70th Scientific Sessions, June 2010, Orlando, FL.
}

complications leading to lower extremity amputations begin as ulcerations $(3,4)$; therefore, proper preventive foot care is key to the management of diabetes (5). Even so, many patients

\section{Key Messages}

- foot ulcers are a serious complication in patients with diabetes

- in a large sample of individuals with diabetes and foot ulcer, those who received care from podiatrists before the onset of a foot ulcer were less likely to have amputation, major amputation and hospitalisation 
- podiatrists have been proposed to serve as gatekeepers for the prevention and management of diabetes-related foot complications

- patients with diabetes and foot ulcer receiving care from podiatrists tend to be older and sicker

with diabetes still do not receive preventive foot care prior to ulceration.

Multidisciplinary care has been described to reduce diabetes-related ulcers and amputations (6) in a variety of health care settings including managed care $(7)$, veteran $(8,9)$, military (10) and Native American (11). As part of a team approach, podiatrists have been proposed to serve as gatekeepers for the prevention and management of diabetes-related foot complications (12,13). A recent analysis of the 5\% Medicare sample from 1991 to 2007 suggested visiting a podiatrist as part of a lower extremity care team in the year prior to a lower extremity complication was protective for undergoing lower extremity amputation (14). Additionally, a retrospective cohort study of 485 patients found that the referral of patients with diabetes mellitus and risk factors for ulceration and limb loss to specialty multidiscipline podiatric medical care may be associated with lower rates of ulceration and major amputation in some patients, thereby reducing health care costs (15).

Using a large retrospective database of patients with diabetes in the USA, this study assessed the association between podiatric care in the prevention of adverse events (amputation, major amputation and hospitalisation) related to foot ulcers. Comparisons were made between patients with pre-ulcer podiatric visits and patients without pre-ulcer podiatric visits using regression adjustment and propensity score weighting to control for potential differences between these groups of patients.

\section{Methods}

Patients were selected from the Truven Health MarketScan Research Databases, which are constructed from fully adjudicated medical and outpatient prescription drug claims. The Commercial Database represents the health care experience of tens of millions of employees and their dependents (annually), covered under a variety of employer-sponsored health plans. The Medicare Supplemental and Coordination of Benefits (COB) Database contains the health care experience of individuals with Medicare supplemental insurance paid by employers. Both the Medicare-covered portion of payment (represented as Coordination of Benefits Amount) and the employer-paid portion are included in this database. The medical claims are linked to outpatient prescription drug claims and person-level enrolment data through encrypted enrollee identifiers. The MarketScan databases conform to the confidentiality requirements of the Health Insurance Portability and Accountability Act of 1996; thus, the study did not require informed consent or Institutional Review Board approval.

\section{Study population}

Patients aged 18 years and older enrolled in the MarketScan Commercial or Medicare databases during years 2005-2008 were selected to the study population if they had a diabetes diagnosis according to ICD-9-CM codes appearing on at least one inpatient claim or two outpatient claims separated by at least 30 days (codes are available in Table A1). Claims for procedures that are diagnostic in nature (e.g. laboratory tests) were not used to establish the diabetes diagnosis.

The index date for the analysis was assigned as the date of the first observed visit with a diagnosis code indicating foot ulcer in 2005-2008. Patients with an index date in 2005 were excluded if they had any previous claims with a diagnosis of foot ulcer in the previous year. All patients were required to have at least 1 year of enrolment prior to the index date. Patients switching health plans within the same employer could be followed as they changed plans, and all patients were followed through to their end of enrolment in any health plan offered by the employer or up until 2009, whichever was later.

Patients were grouped into case (podiatry care) or comparison (no podiatry care) if the patient received care from a podiatrist during the year prior to the index diabetic foot ulcer diagnosis. The primary analyses compared patients without any visits to a podiatrist during the year prior to the index date (comparison) with those having one or more visits (case). An examination was conducted of patients who had three or more visits to a podiatrist prior to the index date (case) and compared their outcomes to patients without any podiatric visits. Because provider specialty code was used to identify podiatry visits, patients were excluded from the comparison cohort (no podiatric care) if provider specialty codes were not available.

Patients with any lower extremity amputation in the year prior to the index date were excluded from the study, based on both procedure (defined below) and diagnosis codes. Patients were also excluded from the case cohort if the claim for the initial podiatric visit indicated a foot ulcer. Thus, the study captured new episodes of care for a diabetic foot ulcer and compared outcomes for patients who received care from a podiatrist prior to the index foot ulcer to patients who did not receive care from a podiatrist prior to the index foot ulcer.

\section{Outcome variables}

Three outcomes were measured: lower extremity amputation, major amputation and hospitalisation. Lower extremity amputation was identified using procedure codes on the claims. A subset of lower extremity amputations were classified as major amputations, defined as amputations occurring at the knee or higher. Inpatient hospitalisation was indicated by a stay in an inpatient facility including at least one night of room and board. A flag was created to indicate the presence of each outcome during a fixed 24-month follow-up period after the index date for patients who could be followed for at least 24 months. Among patients with each outcome, time in days from index (first observed foot ulcer) to the outcome was measured.

\section{Explanatory variables}

Sociodemographic characteristics, plan type, health status and risk factors were also measured. These characteristics 
included: patient age at index; gender; urban residence (defined as residence in a metropolitan statistical area); and whether the primary beneficiary was paid salaried or hourly and US census region (Northeast, North Central, West and South). Two measures were taken from the 2000 census data: median household income by ZIP code of residence as a proxy for income, and percent of college graduates (among residents aged 25 and older) by ZIP as a proxy for education. Plan types included comprehensive, health maintenance organisation (HMO), point-of-service (POS), preferred provider organisation (PPO) and others (e.g. consumer-directed health plan (CDHP) and capitated POS).

Health status variables were measured during the year prior to index. The Charlson comorbidity index (CCI) is an aggregate measure based on diagnoses associated with 19 conditions (16); however, because the CCI does not capture mental health conditions, the number of Psychiatric Diagnostic Groupings (PDGs) was also included. The 12 PDGs include mental health conditions such as alcohol-use disorders, depression and schizophrenia (17). Refill adherence to antidiabetic medications, as indicated by the percent of days covered with antidiabetic medications on hand, was also captured.

Two sets of risk factors were included in the models and also measured during the year prior to the index foot ulcer diagnosis. Patient-level risk factors included cardiovascular disease, nephropathy and diabetes-related eye disease. Footlevel risk factors included neuropathy, peripheral arterial disease, callus and others (e.g. abrasions) (18). Codes for these conditions are detailed in Table A1.

\section{Propensity score weighting}

As patients in the case and comparison groups may be different in terms of demographic characteristics or health status, propensity score weighting was used to adjust for observable differences between the two cohorts in two steps. First, the probability of seeing a podiatrist was estimated using a logistic regression (dependent variable $=1$ if case and 0 if comparison), as a function of the explanatory variables. Two other variables were added to the propensity score models: the number of months a patient was followed over time (enrolment months) and the percent of enrolment within the patient's employer $\times$ health plan using podiatric services (to account for differences in podiatry benefits). Second, cases were assigned a weight of 1 and comparison patients were assigned a weight of $p /(1-p)$, where $p$ is the predicted probability of being a case from the logistic regression (19). With this weighting, estimates are interpreted as the effect of the treatment (care by a podiatrist) on the treated (those who received care from a podiatrist) (20).

Separate propensity score regressions and weights were calculated for each sample (commercial and Medicare-eligible) and also for each analysis (i.e. main analysis where podiatry care is defined as one or more pre-ulcer visits and the sensitivity analysis that defined podiatry care as three or more pre-ulcer podiatry visits).

\section{Statistical analysis}

Two sets of statistical models were estimated. First, Cox proportional hazard models estimated the risk of amputation at time $t$, conditional on survival (i.e. enrolment) to that time $(t)$, controlling for the explanatory variables. Second, the likelihood of each outcome within a fixed length of follow-up, 2 years after diagnosis of foot ulcer, was estimated using logistic regression and the same covariates as the Cox proportional hazard models, with the addition of the year of the index date. Then, the predicted probability of each outcome was estimated (21). Each of these analyses was conducted with and without propensity score weights within the commercial and Medicare-eligible samples.

\section{Results}

We found 20208 commercially insured patients (7597 with podiatrist care and 12611 with no podiatrist care) and 27545 Medicare-eligible patients (13692 with podiatrist care and 13853 with no podiatrist care) meeting all inclusion and exclusion criteria, where podiatrist care was defined as one or more visits to a podiatrist during the year prior to the index foot ulcer (Table 1).

In both the commercial and Medicare samples, patients receiving care from podiatrists were older than patients who did not receive pre-ulcer podiatry care (Table 1). Also, a higher percentage of patients receiving care from podiatrists were females $(P<0 \cdot 001)$. Patients receiving care from podiatrists were more likely to reside in an urban area than those who did not receive care from podiatrists $(P<0 \cdot 001)$.

Health status, as indicated by average scores on the CCI and the number of PDGs, was lower and statistically significant $(P<0.001)$ for patients receiving care from podiatrists, except that differences in PDGs did not reach statistical significance in the commercial sample $(P=0 \cdot 212)$. A greater proportion of patients receiving care from podiatrists had higher values of patient-level and foot-level risk factors measured (all $P<0.01)$ with the exception of nephropathy rates in the Medicare sample where rates did not differ. Adherence to antidiabetic medications, as indicated by a higher medication possession ratio, was greater in patients receiving care from podiatrists $(P<0.001)$.

In both the commercial and Medicare samples, patients receiving care from podiatrists had a longer length of time to amputation than those who did not receive such care (Table 1), without adjusting for differences between patients who did and did not receive pre-ulcer podiatric care. The difference was about 55 (Medicare) to 77 (commercial) days longer until amputation for podiatry patients (both $P<0 \cdot 001$ ). Results were similar for major amputation, except that differences in the time to amputation were not statistically significant in the commercial sample. Patients seen by a podiatrist also had a longer time to hospitalisation of 35 (Medicare) to 64 (commercial) days (all $P<0 \cdot 001$ ).

About $40 \%$ of enrollees could be followed over 24 months. The percent of patients with each of the events (amputation or hospitalisation) within 24 months was significantly lower for patients in the podiatry care group for both the commercial and Medicare samples (all $P<0 \cdot 05$ ). 
Table 1 Comparison of patients with diabetes and foot ulcer (unmatched comparison)*

\begin{tabular}{|c|c|c|c|c|c|c|}
\hline \multirow[b]{2}{*}{ Characteristic } & \multicolumn{3}{|c|}{ Commercial } & \multicolumn{3}{|c|}{ Medicare } \\
\hline & $\begin{array}{l}\text { Podiatrist visit } \\
\text { (case) } \dagger\end{array}$ & $\begin{array}{l}\text { No podiatrist visit } \\
\text { (comparison) }\end{array}$ & $P$-value & $\begin{array}{l}\text { Podiatrist } \\
\text { visit (case) }\end{array}$ & $\begin{array}{c}\text { No podiatrist } \\
\text { visit (comparison) }\end{array}$ & $P$-value \\
\hline$n$ & 7597 & 12611 & & 13692 & 13853 & \\
\hline \multicolumn{7}{|l|}{ Age group, \% } \\
\hline $18-34$ & 1.5 & $2 \cdot 3$ & $<0.001$ & & & \\
\hline $35-44$ & $6 \cdot 0$ & 9.7 & $<0.001$ & & & \\
\hline $45-54$ & $30 \cdot 7$ & $33 \cdot 1$ & $<0.001$ & & & \\
\hline $55-64$ & 61.8 & $54 \cdot 8$ & $<0.001$ & & & \\
\hline $65-74$ & & & & $35 \cdot 8$ & 41.6 & $<0.001$ \\
\hline $75-84$ & & & & $46 \cdot 8$ & $44 \cdot 0$ & $<0.001$ \\
\hline$>85$ & & & & 17.4 & 14.4 & $<0.001$ \\
\hline Age, years (mean $\pm S D$ ) & $55 \cdot 0 \pm 6 \cdot 8$ & $53 \cdot 7 \pm 7 \cdot 6$ & $<0.001$ & $77.6 \pm 6.9$ & $76.7 \pm 6.9$ & $<0.001$ \\
\hline Female & 44.7 & $38 \cdot 1$ & $<0.001$ & 48.5 & 44.4 & $<0.001$ \\
\hline Employee & $66 \cdot 6$ & $68 \cdot 0$ & 0.037 & $81 \cdot 0$ & $81 \cdot 3$ & 0.565 \\
\hline \multicolumn{7}{|l|}{ Insurance plan type, \% } \\
\hline Comprehensive & $10 \cdot 9$ & $9 \cdot 1$ & $<0.001$ & $56 \cdot 1$ & 45.8 & $<0.001$ \\
\hline $\mathrm{HMO}$ & 14.8 & 21.4 & $<0.001$ & 7.5 & $16 \cdot 7$ & $<0.001$ \\
\hline POS/EPO & $11 \cdot 3$ & $8 \cdot 8$ & $<0.001$ & 1.7 & $1 \cdot 1$ & $<0.001$ \\
\hline PPO & 58.5 & $56 \cdot 6$ & 0.009 & 33.5 & 34.9 & 0.014 \\
\hline Other & 4.5 & 4.0 & 0.093 & $1 \cdot 2$ & 1.6 & 0.003 \\
\hline Urban residence & 84.5 & $80 \cdot 1$ & $<0.001$ & $86 \cdot 7$ & $82 \cdot 4$ & $<0.001$ \\
\hline \multicolumn{7}{|l|}{ Geographic region, \% } \\
\hline Northeast & $16 \cdot 1$ & 8.9 & $<0.001$ & $12 \cdot 5$ & 7.9 & $<0.001$ \\
\hline North Central & 31.5 & 27.5 & $<0.001$ & $45 \cdot 0$ & $38 \cdot 2$ & $<0.001$ \\
\hline South & $42 \cdot 4$ & 47.5 & $<0.001$ & $26 \cdot 9$ & 32.7 & $<0.001$ \\
\hline West & 9.7 & $15 \cdot 8$ & $<0.001$ & $15 \cdot 4$ & $21 \cdot 0$ & $<0.001$ \\
\hline Unknown & 0.4 & 0.3 & 0.208 & 0.2 & 0.2 & 0.860 \\
\hline Median household income in ZIP, \$ (mean \pm SD) & $45588 \pm 15579$ & $43459 \pm 14565$ & $<0.001$ & $45869 \pm 15403$ & $44345 \pm 14888$ & $<0.001$ \\
\hline Percent college graduates in ZIP (mean \pm SD) & $0.22 \pm 0.13$ & $0.21 \pm 0.13$ & $<0.001$ & $0.23 \pm 0.13$ & $0.22 \pm 0.13$ & $<0.001$ \\
\hline \multicolumn{7}{|l|}{ Health status $\ddagger$} \\
\hline Charlson comorbidity index & $2.64 \pm 1.74$ & $2.15 \pm 1.74$ & $<0.001$ & $3.17 \pm 1.99$ & $2.82 \pm 1.92$ & $<0.001$ \\
\hline Psychiatric diagnosis groups & $0.18 \pm 0.52$ & $0.17 \pm 0.52$ & 0.212 & $0.19 \pm 0.54$ & $0.17 \pm 0.50$ & $<0.001$ \\
\hline Medication possession ratio & $0.64 \pm 0.36$ & $0.57 \pm 0.38$ & $<0.001$ & $0.65 \pm 0.36$ & $0.63 \pm 0.37$ & $<0.001$ \\
\hline \multicolumn{7}{|l|}{ Patient-level risk factorsł, \% } \\
\hline Cardiovascular & $61 \cdot 2$ & $56 \cdot 6$ & $<0.001$ & $72 \cdot 1$ & 68.4 & $<0.001$ \\
\hline Nephropathy & $16 \cdot 1$ & $15 \cdot 0$ & 0.048 & 20.5 & $21 \cdot 3$ & 0.109 \\
\hline Eye & $19 \cdot 3$ & $15 \cdot 2$ & $<0.001$ & $13 \cdot 6$ & $11 \cdot 3$ & $<0.001$ \\
\hline \multicolumn{7}{|l|}{ Foot-level risk factors $\neq \%$} \\
\hline Neuropathy & $15 \cdot 0$ & $6 \cdot 8$ & $<0.001$ & 8.2 & $5 \cdot 0$ & $<0.001$ \\
\hline Peripheral arterial disease & $20 \cdot 2$ & $17 \cdot 7$ & $<0.001$ & 32.5 & $26 \cdot 6$ & $<0.001$ \\
\hline Callus & $2 \cdot 6$ & 1.3 & $<0.001$ & 3.7 & 1.3 & $<0.001$ \\
\hline Months of enrolment after index & $23 \cdot 22 \pm 15 \cdot 04$ & $21.85 \pm 14.93$ & $<0.001$ & $23 \cdot 26 \pm 15 \cdot 50$ & $21 \cdot 24 \pm 15 \cdot 24$ & $<0.001$ \\
\hline \multicolumn{7}{|l|}{ Year of index date, \% } \\
\hline 2005 & $24 \cdot 1$ & $23 \cdot 6$ & 0.418 & $24 \cdot 25$ & $28 \cdot 28$ & $<0.001$ \\
\hline 2006 & 23.8 & 21.9 & 0.002 & $26 \cdot 79$ & 23.92 & $<0.001$ \\
\hline 2007 & $25 \cdot 3$ & $25 \cdot 3$ & 0.925 & $24 \cdot 81$ & $23 \cdot 86$ & 0.068 \\
\hline 2008 & $26 \cdot 8$ & $29 \cdot 2$ & $<0.001$ & $24 \cdot 15$ & 23.94 & 0.675 \\
\hline \multicolumn{7}{|l|}{ Measures } \\
\hline$n$ & 7597 & 12611 & & 13692 & 13853 & \\
\hline$n$ with lower extremity amputation & 811 & 1682 & & 1042 & 1240 & \\
\hline $\begin{array}{l}\text { Time to amputation (days) } \\
n \text { with major amputation }\end{array}$ & $\begin{array}{c}284 \cdot 0 \pm 347 \cdot 8 \\
179\end{array}$ & $\begin{array}{c}207 \cdot 4 \pm 302 \cdot 6 \\
380\end{array}$ & $<0.001$ & $\begin{array}{c}265 \cdot 2 \pm 325 \cdot 3 \\
280\end{array}$ & $\begin{array}{c}210 \cdot 1 \pm 298 \cdot 0 \\
407\end{array}$ & $<0.001$ \\
\hline $\begin{array}{l}\text { Time to major amputation (days) } \\
n \text { with hospitalisation }\end{array}$ & $\begin{array}{c}332 \cdot 5 \pm 280 \cdot 2 \\
3475\end{array}$ & $\begin{array}{c}271 \cdot 0 \pm 328 \cdot 4 \\
6451\end{array}$ & 0.051 & $\begin{array}{c}278 \cdot 9 \pm 312 \cdot 3 \\
8576\end{array}$ & $\begin{array}{c}215 \cdot 5 \pm 284 \cdot 1 \\
8592\end{array}$ & 0.006 \\
\hline Time to hospitalisation (days) & $284 \cdot 3 \pm 320 \cdot 1$ & $220 \cdot 5 \pm 290 \cdot 2$ & $<0.001$ & $288.4 \pm 305.5$ & $253 \cdot 2 \pm 291.5$ & $<0.001$ \\
\hline \multicolumn{7}{|l|}{ Measures (within 2 years) } \\
\hline$n$ with 2-year follow-up & 3304 & 4914 & & 5990 & 5423 & \\
\hline Lower extremity amputation, \% & $10 \cdot 3$ & $12 \cdot 4$ & 0.003 & $7 \cdot 2$ & 8.8 & 0.002 \\
\hline Major amputation, \% & 1.7 & 2.5 & 0.021 & 1.7 & $2 \cdot 7$ & $<0.001$ \\
\hline Hospitalisation, \% & $44 \cdot 2$ & 51.6 & $<0.001$ & $58 \cdot 2$ & $60 \cdot 2$ & 0.036 \\
\hline
\end{tabular}

$\mathrm{HMO}$, health maintenance organisation; POS, point-of-service; PPO, preferred provider organisation.

*Data source: 2004-2009 MarketScan Databases.

tCases are patients with one or more visits to a podiatrist during the year prior to their index foot ulcer. Comparison patients did not have visits to a podiatrist during the year prior to their index foot ulcer.

¥Measured 1 year prior to index date. 
After adjusting for covariates, patients receiving care from podiatrists had lower rates of amputation, major amputation and hospitalisation than those who did not receive care from podiatrists in all model specifications: the unweighted and propensity score-weighted analyses for both the commercial and Medicare samples (all $P<0.001$ ) (Table 2). For example, patients receiving care from podiatrists in the commercial unweighted sample had a hazard of amputation that was $25.2 \%$ lower than patients without podiatric care [hazard ratio $(\mathrm{HR})=0.748,95 \%$ confidence interval $(\mathrm{CI})$ : $0 \cdot 686-0.816]$ and $20.6 \%$ lower for the Medicare unweighted sample $(\mathrm{HR}=0.794,95 \%$ CI: $0.729-0.864)$. Results were similar for the weighted samples. Commercial patients receiving pre-ulcer care from a podiatrist had a $25.0 \%$ lower hazard of lower extremity amputation than patients without care from a podiatrist in the commercial weighted sample - this was $23.4 \%$ for the Medicare weighted sample.

To assess whether a greater number of pre-ulcer podiatric visits had a larger effect on the events, we conducted a sensitivity analysis comparing patients with three or more pre-ulcer podiatric visits to the comparison group without pre-ulcer visits to a podiatrist. Hazard ratios estimated in the sensitivity analysis were similar to the main analysis comparing patients with one pre-ulcer podiatric visit to patients without podiatric visits. Patients with three or more pre-ulcer podiatric visits in the weighted commercial sample had $23.7 \%$ lower risk of lower extremity amputation (HR $=0.763,95 \%$ CI: $0.688-0.845)$ and a $25.7 \%$ lower hazard in the weighted Medicare sample (HR $=0.743$, 95\% CI: $0.675-0.817)$ than the comparison group $(26.2 \%$ and $23.7 \%$ in the unweighted commercial and Medicare samples, respectively).

Kaplan-Meier curves for lower extremity amputation are shown in Figure 1 (weighted samples) and show that the patients with a podiatrist visit had a longer time to amputation than those without podiatry visits for both the commercial (Panel A) and Medicare (Panel B) samples.

For the sample of patients with at least 2 years of follow-up after the index date, the likelihood of each event (amputation or hospitalisation) occurring within 2 years of the index date was significantly lower in patients receiving care from podiatrists (all $P<0.01$ ) in both the commercial and Medicare propensity score-weighted samples (Figure 2 ). Similar results were found in the unweighted samples (all $P<0.01$, not shown).

\section{Discussion}

Podiatrists are medical practitioners focusing on management and treatment of the foot and are considered by many health care professionals to be the primary source of specialised foot care in the USA. The more recent practice model developed by the medical community describes the podiatrist as a 'Limb Preservationist' (13). This new model focuses not only on the contribution of podiatrists but also on several members of an interdisciplinary team that medically and surgically manages complicated and complex diabetic foot disorders.

In this study of two large samples of individuals with diabetes and foot ulcer (commercially insured and Medicare-eligible), we found that those who received care

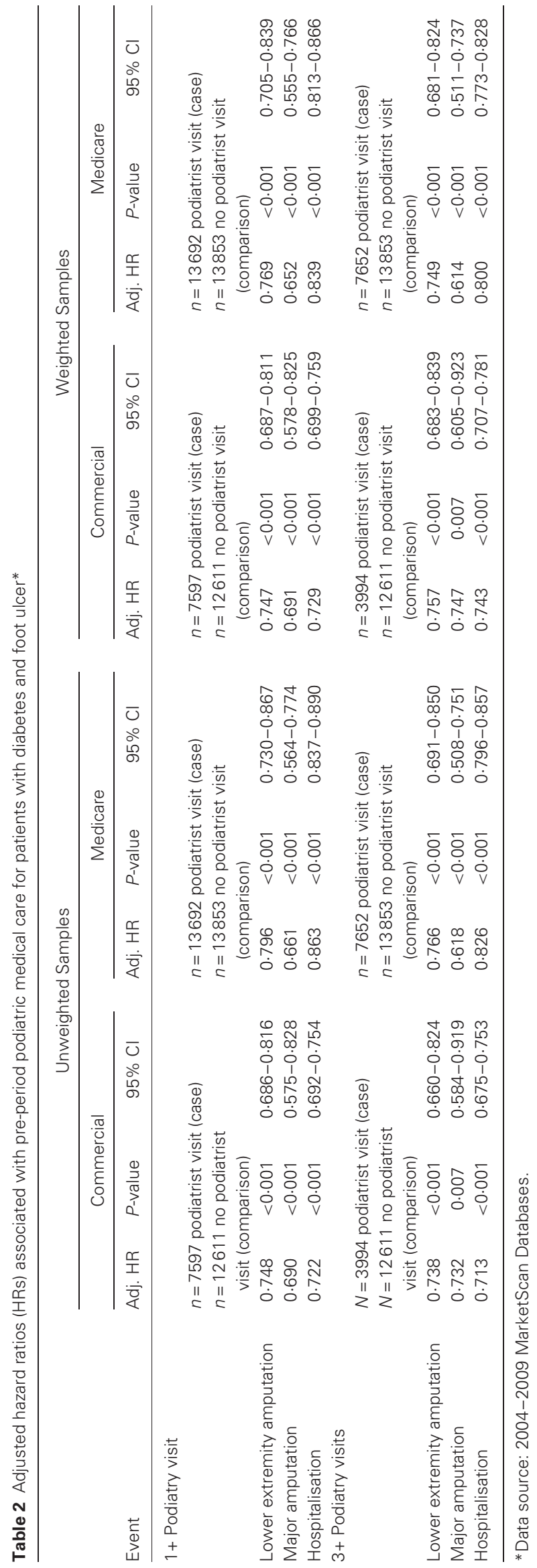




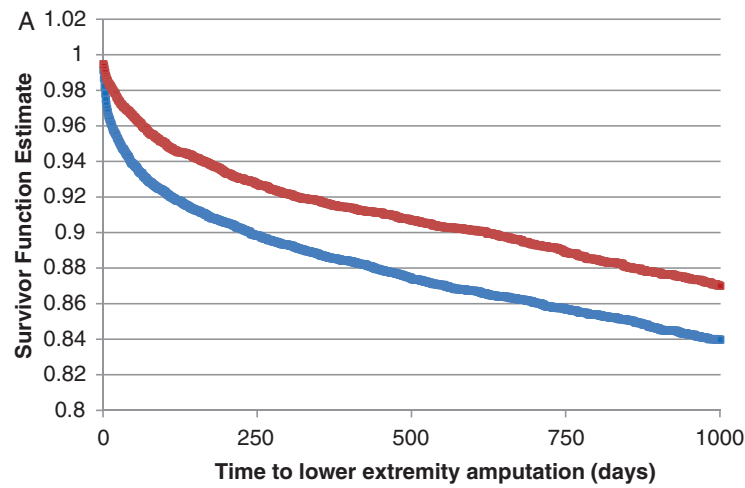

$\simeq$ No pre-period podiatrist visit $\_1+$ pre-period podiatrist visit

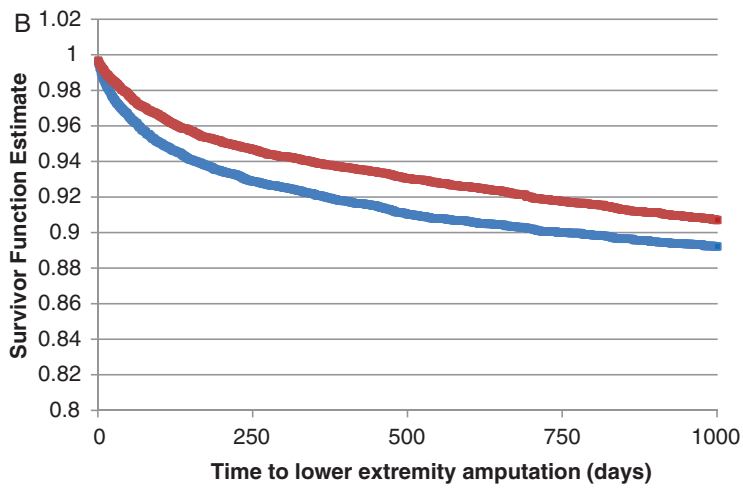

$\longrightarrow$ No pre-period podiatrist visit $\longrightarrow 1+$ pre-period podiatrist visit

Figure 1 Kaplan-Meier curve for time to lower extremity amputation. (A) Commercially insured patients $(n=7597$ case, $n=12611$ comparison). (B) Medicare-eligible patients ( $n=13692$ case, $n=13853$ comparison). Data source: 2004-2009 MarketScan Databases. Estimates are shown using propensity score weights to account for differences between case and comparison patients. Podiatry care group had one or more podiatry visits during the year prior to the index foot ulcer diagnosis; the no podiatry group had no such visits.

from podiatrists before the onset of a foot ulcer were less likely to have adverse events such as amputation, major amputation and hospitalisation. We also found that there were systematic differences between patients with diabetes and foot ulcer receiving care from podiatrists and patients with diabetes and foot ulcer who did not receive care from podiatrists. Namely, patients with diabetes receiving care from podiatrists tend to be older and sicker than those who do not receive care from podiatrists. Adjusting for these differences via regression adjustment or a combination of propensity score weighting and regression adjustment yielded similar results - a significant reduction in the likelihood of and time to each of the adverse events.

Our findings are in agreement with results observed in previous studies of podiatric care and lower extremity amputations. Sloan et al. assessed a 5\% sample of Medicare claims between 1991 and 2007 for patients with diabetes-related lower extremity complications. The study authors concluded that patients having received care from both a podiatrist and a lower extremity care specialist for an ulceration were

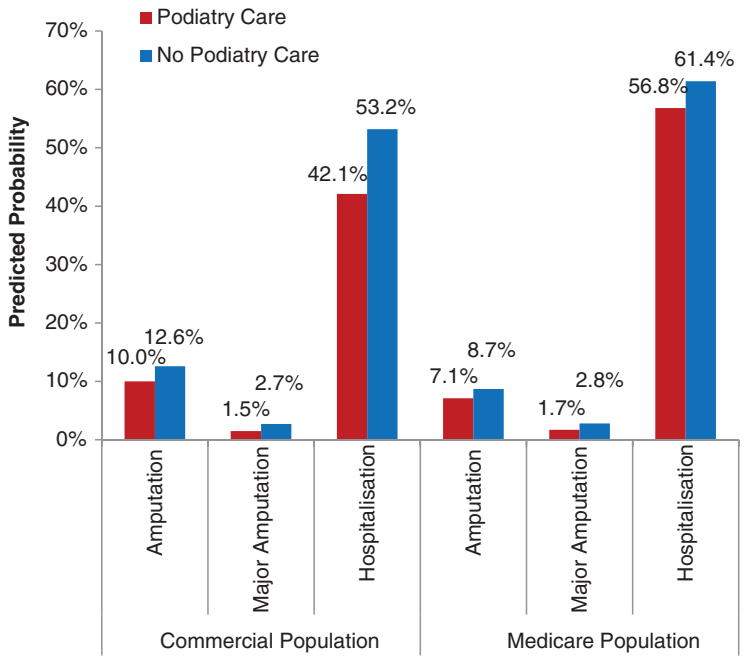

Figure 2 Predicted probability of outcome within 2 years, weighted samples. Data source: 2004-2009 MarketScan Databases. All comparisons between podiatry care and no podiatry care were statistically significant at $P<0.01$. Estimates are shown using propensity score weights to account for differences between case and comparison patients. Podiatry care group had one or more podiatry visits during the year prior to the index foot ulcer diagnosis; the no podiatry group had no such visits.

$36 \%$ less likely to have had a lower extremity amputation compared to those who had only seen another type of physician (14). In the same study, those with care provided by only a podiatrist were also less likely to have had a lower extremity amputation (44\% less likely) but this was not statistically significant. This study shows a lower likelihood of amputation after receipt of podiatric care, but we are unable to distinguish patients who receive other specialised lower extremity care from those who do not.

More recently, Carls et al. also examined the effects of podiatric care in the treatment of diabetic foot ulcers, including populations of commercially insured and Medicare patients. This analysis observed that podiatric care was associated with a 2.67 and 1.35 percentage point reduction in amputation rates in a commercially insured and Medicare-eligible population, respectively (22).

Several other studies also address the value of podiatric care. A study of 91 patients in Austria with recently healed foot ulcers and diabetes found a significant reduction in the amount of time to ulcer recurrence among patients randomised to podiatrist care (HR: 0.52, 95\% CI: 0.30-0.93) (23). A second study analysed the experience of 530 patients in Finland who were receiving antidiabetes medications, but had no obvious need for a podiatrist. Half the sample was randomised to receive podiatrist care and the other half to receive written instructions (24). At the end of 1-year follow-up, the prevalence of callosities in regions other than the calcaneal region decreased, as did the diameter of these callosities in patients receiving care from podiatrists. Lavery et al. (7) reported that a team including podiatrists implemented a foot risk-based disease management program for diabetes foot care in a US-managed care program and 
after 2 years, there was a $47 \%$ reduction in amputations, 38\% reduction in hospital admissions and $70 \%$ reduction in skilled nursing facility admissions.

There are potential limitations to this analysis. First, we did not extract the specific features of care or other types of providers involved in the ulcer care. We measured receipt of care from podiatrists prior to the onset of a foot ulcer to determine whether these process differences led to differences in outcomes. The aim of this study was to measure podiatry in terms of its educational and holistic benefits during a subsequent ulceration, not to measure process of care differences within the episode of care. This strategy is supported in the literature as podiatry care in patients with diabetes resulted in higher knowledge scores and higher selfcare scores at 1 year (24). This is also supported in this study as patients seeing podiatrists were also more adherent to medication use as indicated by significantly higher medication possession ratios. Second, we focused our analysis on those patients with foot ulcer who did not have an amputation or an ulcer in the previous year, which may limit generalisability to other patient populations. However, this also underscores the magnitude of these findings as patients with a previous foot ulcer tend to be sicker than patients without a history of foot ulcer, an observation supported by the significant differences in CCI between our case and comparison cohorts. Third, our results are based on administrative claims data, and all the limitations inherent in coding systems and data designed for reimbursement apply to this study.

In summary, in a sample of patients with diabetes and foot ulcer, we found that pre-ulcer care by a podiatrist appears to be associated with lower rates of lower extremity amputation and hospitalisation.

\section{Acknowledgements}

This study was funded by American Podiatric Medical Association. TG, EB, GC and JG were salaried employees of Thomson Reuters (now Truven Health Analytics) at the time the study was conducted - Thomson Reuters was under contract for the study funded by the American Podiatric Medical Association (APMA); TG has been involved in projects sponsored by Pfizer Inc and Bristol Myers Squibb; VD is a Volunteer Position Chair for Clinical Practice Guidelines for the APMA; JW is a member of the Clinical Practice Advisory Committee (CPAC) for the APMA; JC is the Director of Scientific Affairs at the APMA; RD does not have conflicts of interest to report and $\mathrm{MG}$ is a trustee for APMA.

\section{Author contribution}

TG researched data, contributed to the discussion, wrote the manuscript and reviewed/edited the manuscript; VD researched data, contributed to the discussion, wrote the manuscript and reviewed/edited the manuscript; JW contributed to the discussion and reviewed/edited the manuscript; JC contributed to the discussion and reviewed/edited the manuscript; EB researched data, contributed to the discussion and reviewed/edited the manuscript; RD contributed to the discussion and reviewed/edited the manuscript; MG contributed to the discussion and reviewed/edited the manuscript; GC contributed to the discussion, reviewed data and reviewed/edited the manuscript and JG researched data and contributed to the results. All authors provided final approval of the version to be published.

\section{References}

1. Singh N, Armstrong DG, Lipsky BA. Preventing foot ulcers in patients with diabetes. JAMA 2005;293:217-28.

2. Apelqvist J, Larsson J, Agardh CD. Long-term prognosis for diabetic patients with foot ulcers. J Intern Med 1993;233:485-91.

3. Armstrong D, Lavery L. Diabetic foot ulcers: prevention, diagnosis, and classification. Am Fam Physician 1998;57:1325-32.

4. Centers for Disease Control and Prevention. Working together to manage diabetes: a guide for pharmacy, podiatry, optometry, and dental professionals. Atlanta: U.S. Department of Health and Human Services, Public Health Service, Centers for Disease Control and Prevention, National Center for Chronic Disease Prevention and Health Promotion, 2007.

5. Mayfield JA, Reiber GE, Sanders LJ, Janisse D, Pogach LM. Preventive foot care in people with diabetes. Diabetes Care 1998;21:2161-77.

6. Edmonds ME, Blundell MP, Morris ME, Thomas EM, Cotton LT, Watkins PJ. Improved survival of the diabetic foot: the role of a specialised foot clinic. Q J Med 1986;60:763-71.

7. Lavery LA, Wunderlich RP, Tredwell JL. Disease management for the diabetic foot: effectiveness of a diabetic foot prevention program to reduce amputations and hospitalizations. Diabetes Res Clin Pract 2005;70:31-7.

8. Mayfield JA, Reiber GE, Maynard C, Czerniecki J, Sangeorzan B. The epidemiology of lower-extremity disease in veterans with diabetes. Diabetes Care 2004;27(Suppl 2):B39-44.

9. Wrobel JS, Robbins JM, Charns MP, Bonacker KM, Reiber GE, Pogach L. Diabetes-related foot care at 10 Veterans Affairs medical centers: must do's associated with successful microsystems. Jt Comm J Qual Patient Saf 2006;32:206-13.

10. Driver VR, Madsen J, Goodman RA. Reducing amputation rates in patients with diabetes at a military medical center: the Limb Preservation Service model. Diabetes Care 2005;28:248-53.

11. Rith-Najarian S, Branchaud C, Beaulieu O, Gohdes D, Simonson G, Mazze R. Reducing lower-extremity amputations due to diabetes. Application of the staged diabetes management approach in a primary care setting. J Fam Pract 1998;47:127-32.

12. Frykberg RG. Team approach toward lower extremity amputation prevention in diabetes. J Am Podiatr Med Assoc 1997;87:305-12.

13. Driver VR, Griffis C. The role of the podiatric physician in wound care. In: Krasner DL, Rodeheaver GT, Sibbald RG, editors. Chronic wound care: a clinical source book for health care professionals, 4 edn. Malvern: HMP Communications, 2007:389-93.

14. Sloan FA, Feinglos MN, Grossman DS. Receipt of care and reduction of lower extremity amputations in a nationally representative sample of U.S. elderly. Health Serv Res 2010;45:1740-62.

15. Driver VR, Goodman RA, Fabbi M, French MA, Andersen CA. The impact of a podiatric lead limb preservation team on disease outcomes and risk prediction in the diabetic lower extremity: a retrospective cohort study. J Am Podiatr Med Assoc 2010;100:235-41.

16. D'Hoore W, Bouckaert A, Tilquin C. Practical considerations on the use of the Charlson Comorbidity Index with administrative data bases. J Clin Epidemiol 1996;49:1429-33.

17. Ashcraft MLF, Fries BE, Nerenz DR, Falcon SP, Srivastava SV, Lee CZ, Berki SE, Errera P. A psychiatric patient classification system: an alternative to diagnosis-related groups. Med Care 1989;27:543-57.

18. Boulton AJM, Armstrong DG, Albert SF, Frykberg RG, Hellman R, Kirkman MS, Lavery LA, LeMaster JW, Mills JL, Mueller MJ, 
Sheehan P, Wukich DK. Comprehensive risk examination and foot assessment: a report of the Task Force of the Foot Care Interest Group of the American Diabetes Association, with endorsement by the American Association of Clinical Endocrinologists. Diabetes Care 2008;31:1679-85.

19. Guo S, Fraser MW. Propensity score analysis: statistical methods and applications. Thousand Oaks: SAGE Publications, 2010.

20. Winship C, Morgan SL. The estimation of causal effects from observational data. Annu Rev Sociol 1999;25:659-706.

21. Kleinman LC, Norton EC. What's the risk? A simple approach for estimating adjusted risk measures from nonlinear models including logistic regression. Health Serv Res 2009;44:288-302.

22. Carls GS, Gibson TB, Driver VR, Wrobel JS, Garoufalis MG, DeFrancis RR, Wang S, Bagalman JE, Christina JR. The economic value of specialized lower-extremity medical care by podiatric physicians in the treatment of diabetic foot ulcers. $J$ Am Podiatr Med Assoc 2011;101:93-115.

23. Plank J, Haas W, Rakovac I, Gorzer E, Sommer R, Siebenhofer A, Pieber TR. Evaluation of the impact of chiropodist care in the secondary prevention of foot ulcerations in diabetic subjects. Diabetes Care 2003;26:1691-5.

24. Rönnemaa T, Hämäläinen H, Toikka T, Liukkonen I. Evaluation of the impact of podiatrist care in the primary prevention of foot problems in diabetic subjects. Diabetes Care 1997;20:1833-7.

\section{APPENDIX}

Table A1 Codes for patient-level and foot-level risk factors*

\begin{tabular}{|c|c|c|}
\hline Category & ICD-9 & Description \\
\hline \multicolumn{3}{|c|}{ Codes applied for patient-level risk factors } \\
\hline Cardiology & 401.xx & Essential hypertension \\
\hline Cardiology & 402.xx & Hypertensive heart disease \\
\hline Cardiology & 403.xx & Hypertensive renal disease \\
\hline Cardiology & 404.xx & $\begin{array}{l}\text { Hypertensive heart and renal } \\
\text { disease }\end{array}$ \\
\hline Cardiology & 405.xx & Secondary hypertension \\
\hline Cardiology & $415.0 x$ & Coronary artery disease \\
\hline Cardiology & 414.00 & Arteriosclerotic heart disease \\
\hline Cardiology & 428.0 & Congestive heart failure \\
\hline Cardiology & 429.2 & $\begin{array}{l}\text { Arteriosclerotic cardiovascular } \\
\text { disease }\end{array}$ \\
\hline Cardiology & 429.9 & Heart disease, unspecified \\
\hline Eye & $362.0 x$ & Retinopathy \\
\hline Nephropathy & $580 . x x$ & Acute glomerulonephritis \\
\hline Nephropathy & $581 . x x$ & Nephrotic syndrome \\
\hline Nephropathy & 582.xx & Chronic glomerulonephritis \\
\hline Nephropathy & 583.xx & $\begin{array}{l}\text { Nephritis and nephropathy not } \\
\text { specified }\end{array}$ \\
\hline Nephropathy & $584 . x x$ & Acute renal failure \\
\hline Nephropathy & $585 . x x$ & Chronic renal failure \\
\hline Nephropathy & 586.xx & Renal failure unspecified \\
\hline Nephropathy & 587.xx & Renal sclerosis unspecified \\
\hline Nephropathy & $588 . x x$ & $\begin{array}{l}\text { Disorders resulting from impaired } \\
\text { renal functioning }\end{array}$ \\
\hline Nephropathy & 589.xx & Small kidney of unknown cause \\
\hline \multicolumn{3}{|c|}{ Codes applied for foot-level risk factors } \\
\hline Callus & 700 & Corn, clavus, callus \\
\hline Neuropathy & 355.0 & $\begin{array}{l}\text { Peripheral neuritis/neuralgia, acute, } \\
\text { sciatic nerve }\end{array}$ \\
\hline Neuropathy & 355.2 & $\begin{array}{l}\text { Peripheral neuritis/neuralgia, acute, } \\
\text { femoral nerve }\end{array}$ \\
\hline Neuropathy & 355.3 & $\begin{array}{l}\text { Peripheral neuritis/neuralgia, acute, } \\
\text { lateral popliteal nerve }\end{array}$ \\
\hline
\end{tabular}

Table A1 Continued

\begin{tabular}{|c|c|c|}
\hline Category & ICD-9 & Description \\
\hline Neuropathy & 355.4 & $\begin{array}{l}\text { Peripheral neuritis/neuralgia, acute, medial } \\
\text { popliteal nerve }\end{array}$ \\
\hline Neuropathy & 355.5 & $\begin{array}{l}\text { Peripheral neuritis/neuralgia, acute, } \\
\text { posterior tibial nerve }\end{array}$ \\
\hline Neuropathy & 355.6 & $\begin{array}{l}\text { Peripheral neuritis/neuralgia, acute, plantar } \\
\text { nerve }\end{array}$ \\
\hline Neuropathy & 355.7 & $\begin{array}{l}\text { Peripheral neuritis/neuralgia, acute, due to } \\
\text { infection }\end{array}$ \\
\hline Neuropathy & 355.79 & $\begin{array}{l}\text { Peripheral neuritis/neuralgia, acute, } \\
\text { saphenous nerve }\end{array}$ \\
\hline Neuropathy & 355.8 & $\begin{array}{l}\text { Peripheral neuritis/neuralgia, acute, lower } \\
\text { limb, polyneuritis }\end{array}$ \\
\hline Neuropathy & 357.2 & $\begin{array}{l}\text { Polyneuropathy in diabetes (always code } \\
\text { first the diabetes, 250.6X) }\end{array}$ \\
\hline Neuropathy & 357.4 & $\begin{array}{l}\text { Polyneuropathy in other diseases classified } \\
\text { elsewhere (code underlying disease first) }\end{array}$ \\
\hline Neuropathy & 713.5 & Charcot \\
\hline Neuropathy & 782.0 & Numbness \\
\hline PAD & 440.20 & $\begin{array}{l}\text { Arteriosclerosis/atherosclerosis, } \\
\text { unspecified }\end{array}$ \\
\hline PAD & 440.21 & $\begin{array}{l}\text { Arteriosclerosis/atherosclerosis with } \\
\text { intermittent claudication }\end{array}$ \\
\hline PAD & 440.22 & $\begin{array}{l}\text { Arteriosclerosis/atherosclerosis, with rest } \\
\text { pain }\end{array}$ \\
\hline PAD & 440.23 & $\begin{array}{l}\text { Arteriosclerosis/atherosclerosis with } \\
\text { ulceration (use additional code } \\
\text { 707.10-707.9) }\end{array}$ \\
\hline PAD & 440.24 & $\begin{array}{l}\text { Arteriosclerosis/atherosclerosis, with } \\
\text { gangrene }\end{array}$ \\
\hline PAD & 440.4 & $\begin{array}{l}\text { Artery of the extremities, chronic total } \\
\text { occlusion }\end{array}$ \\
\hline PAD & 443.1 & Buerger's disease \\
\hline PAD & 443.81 & $\begin{array}{l}\text { Peripheral vascular disease of diabetes } \\
\text { (code underlying diabetes first } 250.7 X \text { ) }\end{array}$ \\
\hline PAD & 443.9 & Peripheral vascular disease \\
\hline PAD & 451.0 & Phlebitis, superficial \\
\hline PAD & 451.11 & Phlebitis, femoral vein (deep) (superficial) \\
\hline PAD & 451.19 & $\begin{array}{l}\text { Phlebitis, other (femoropopliteal vein, tibial } \\
\text { vein, popliteal vein) }\end{array}$ \\
\hline PAD & 451.2 & Phlebitis, unspecified \\
\hline PAD & 454.0 & Varicose vein, with ulceration \\
\hline PAD & 454.1 & Stasis dermatitis, with inflammation \\
\hline PAD & 454.2 & $\begin{array}{l}\text { Varicose vein, with ulceration and } \\
\text { inflammation }\end{array}$ \\
\hline PAD & 454.8 & $\begin{array}{l}\text { Varicose vein with other complications } \\
\text { (oedema, pain, swelling) }\end{array}$ \\
\hline PAD & 454.9 & Varicose vein, asymptomatic \\
\hline PAD & 459.11 & Postphlebitic syndrome with ulcer \\
\hline PAD & 459.12 & Postphlebitic syndrome with inflammation \\
\hline PAD & 459.13 & $\begin{array}{l}\text { Postphlebitic syndrome with ulcer and } \\
\text { inflammation }\end{array}$ \\
\hline PAD & 459.81 & $\begin{array}{c}\text { Venous insufficiency (use additional code } \\
\text { for any associated ulcer 707.10-707.9) }\end{array}$ \\
\hline
\end{tabular}

PAD, peripheral artery disease.

* Other Codes: Diabetes: ICD-9-CM: 250.xx (exclude: 648.8x). Foot ulcer: ICD-9-CM: 707.10, 707.12, 707.13, 707.14, 707.15. Lower extremity amputation: ICD-9-CM: 84.11; CPT-4: 10180, 12020, 12021, 27880, 27881, 27882, 27884, 27886, 27888, 28116, 28126, 28153, 28160, 28800, 28805, 28810, 28820, 28825. Major amputation: CPT-4: 27880, 27881, 27882. 